\title{
EcoDesign strategy wheel: appliance in a "Santa-Cruz" Sundial
}

\author{
Luana Lott Alves, Cinthia Gonçalves, Camila Mattos, Tainá Bonato, Eduardo Romeiro Filho \\ Laboratório Integrado de Design e Engenharia do Produto, Departamento de Engenharia de Produção, Universidade Federal de Minas Gerais \\ e-mails: luanalott@gmail.com; cinthiamogo@yahoo.com.br; camilamattos05@gmail.com; tatabonato@gmail.com; romeiro@ufmg.br
}

\begin{abstract}
In a context where environmental questions have been gaining increasingly importance, for both the present legislation and consumers' requirements, several strategies can be adopted by companies that wish to achieve sustainability. The verification list for the "Design for The Life Cycle" is an approach that provides the qualitative evaluation of improvement opportunities in a certain product, in terms of its eco-efficiency. This paper presents the evaluation of the product "Santa-Cruz" Sundial, produced by a Brazilian games' company. An analysis of multiple aspects of the product was made, these being: sizing, materials, production, usage, maintenance, package, final disposal, among others. This assessment was made by assigning the following classification to each one of these criteria: A - ideal situation (the standard was considered in its overall); B - situation to explore (There are opportunities of improvement); C - Urgent need for action (the standard was never considered or the solution is yet unknown for it).
\end{abstract}

Keywords: design for the environment, design for the life cycle, eco-efficiency, life cycle analysis.

\section{Introduction}

The process of product development has been under the crescent influence of product life cycle related questions. Since the first approaches related to manufacturing and assembly that originated the DfMA(Design for Manufacture and Assembly) method back in the 1960 decade (KUO; HUANG; ZHANG, 2001; BOOTHROYD; DEWHURST, 1991), several tools have emerged, with their focus on the incorporation of aspects that used to be disregarded by the product design process. Among these are the quality (with the DfQ, or Design for Quality approach), the disassembly (DfD, Design for Disassembly), and others (HUANG, 1996). However, one of the most relevant aspects has been the environmental sustainability of products and processes and several approaches relate to these facets, namely: Ecodesign, cleaner production systems, and, most recently, Design for Sustainability. As an effect, the questions related to the recent climate change observed in the planet, in addition to economic changes that arose from the financial globalization in the 1980 s and the economical growth of Asian countries (especially China) bring important challenges to the development of new products and to the model of industrial production present on the 20th century (ZHANG et al., 2008).

Given this scenario, this article presents the application of the EcoDesign strategy wheel (Figure 1), which is a tool focused on Design for Sustainability standards, in a wooden watch produced by a small company. This tool adopts a product design perspective, and allows to systematically reviewing the entire product's life cycle (VAN HEMEL, 1998; VAN HEMEL; CRAMER, 2002; FRAZÃO; PENEDA; FERNANDES, 2003). This research was made by means of a study case with elements of participatory research, which included: visits to the company; interviews with people from the management, product design and production departments; and the analysis of the product, suggested by the company. This analysis showed that the product, whose end of life cycle isn't certain, has characteristics that make it inadequate to its goals and reduce considerably its lifespan. Lastly, some indications for improvement will be presented, showing that tools for Design for Sustainability and Simplified Analysis of Life Cycle can be satisfactorily utilized, even by small companies.

\section{Literature review}

The approaches turned to life cycle and sustainability resume the first half of the 20th century, when the impacts of the environment pollution, like the acid rain, begin to call the attention of developed countries (FORNARO, 2006). These problems are not of recent nature, although the relation between industrialization and environmental damage (in particular if connected to human health) has been observed for a longer time, for example in the known case of mercury contamination in the Minamata Bay, Japan, in the 1950s (HOLLAND; BLOOD; SHAFFER, 2003). 


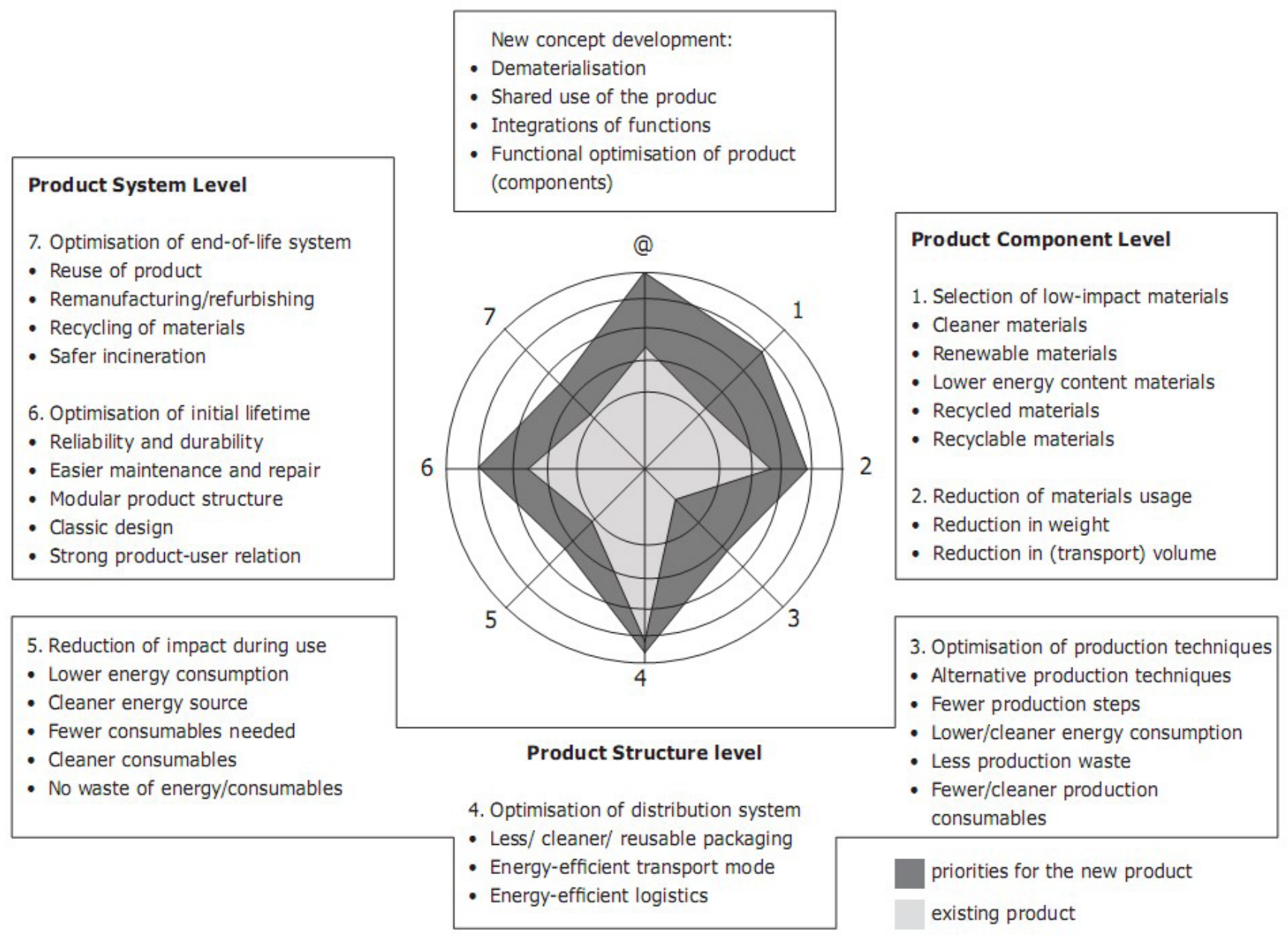

Figure 1. EcoDesign strategy wheel. Source: Wikipedia (2015).

The environmental aware (UNITED..., 2001) begins in the industry, with the implementation of "end of tube" tools, such as filters and systems that prevent the emission of effluents to the environment, although these do not bring considerable changes in the system itself. A second step would be the adoption of cleaner production systems, where alterations in the manufacturing systems are made aiming the reduction of the emission of effluents, instead of only preventing their arrival in the environment (ROHRICH; CUNHA, 2004). Even this approach has its limits, considering the fact that the adopted technology is often inherently polluting, as for example in the utilization of heavy metals or other dangerous components as raw materials.

One alternative of solution is in the Ecodesign or Design for the Environment, that presupposes that the decisions that have environmental impact are taken during the product design process (VAN HEMEL; BREZET, 1997). Indeed, the product design decisions decisively influence the environmental impacts generated by the product. Therefore the importance of product design tools that anticipate environmental problems related to the product, allowing the design team to take adequate decisions regarding environmental aspects of the product (UNITED..., 1996).

\section{Material and methods}

The method adopted in this paper is based on the work by Van Hemel (1998), described by Frazão, Peneda and Fernandes (2003), which proposes the adoption of checklists verifying 14 aspects considered relevant in the product lifecycle, including phases of premanufacture, manufacture, distribution, use and end of life. For each aspect, a list of questions was formulated, and each one was evaluated according to the following rank: A (IDEAL SITUATION, when the criterion was considered as a whole), B (SITUATION TO EXPLORE, when there are opportunities for improvement) or C (NEEDS ACTION URGENT, when the criterion was not considered or the solution for it is still unknown). The evaluated aspects are listed below: 


\subsection{Premanufacture}

1. Optimization of the Function

2. Savings of natural resources

3. Use of renewable and sufficiently available resources

4. Prevention/minimization of hazardous substances' use

\subsection{Manufacture}

5. Streamlining consumption (raw materials, energy, water)

6. Prevention/minimization of pollution emissions and waste

\subsection{Distribution}

7. Optimization of the packaging system

8. Implementation of an adequate logistics system

\subsection{Use}

9. Increase of product durability

10. Prevention/minimization of product utilization impacts

\subsection{End of life}

\section{Optimization of disassembly}

12. Optimization of product reuse

13. Optimization of recycling materials

14. Appropriate discard of unrecoverable materials

This way, the analysis of a selected product from a games' company located in Lagoa Santa, Minas Gerais state, was performed. The company also has a carpentry shop for production of wood components of their products.

\section{Case study}

The study was conducted as a segment of a research project developed in the company. The studied company can be characterized as small and was established in the mid-1990s. It has an extensive line of approximately 150 products, mainly focusing games to the market of corporate gifts. This very specific market allows products to be developed from extensive research (carried out by the owners) about traditional games in Brazil and in rest of the world. This makes their products expensive, but this aspect is offset by the high value associated with the products. They are usually intended for a consumer market that values and preserves the product for a long time; it is not considered a "fashionable" or disposable item (it is usually considered a decorative and "good taste" item).

These characteristics make it desirable that the product has a long useful life. Its immediate replacement is not an objective of the company. Many customers become collectors, so company's portfolio of products is always in expansion. These features significantly increase production costs, thus there is a need to prioritize a flexible production system and an appropriate system for product development.

The product analyzed was the "Santa Cruz" Watch (Figure 2), consisting of a wooden base, with a display in paper (glued on the base), a "gnomom" (device whose shading indicates the hours of the day) of metal and dipping compass. The basic measurements are $11.5 \times 11.5 \times 5 \mathrm{~cm}$. The production process is quite simple, with a base made of wood (in one piece), on top of which is pasted printed paper and affixed the dipping compass. Finally the gnomom is fixed, by fitting and gluing. The results of the analysis, made by following the steps in the method, will be presented below:

\subsection{Premanufacture}

\subsubsection{Optimization of the function}

According to the analysis, it was possible to identify improvement possibilities in two aspects of the product, namely: consumer expectations and use of resources in cascade. With regard to consumer expectations, the product has potential for upgrades, since the fragility of the material (gnomon) causes the product to deteriorate quickly, which is against its proposed durability. However, the company has realized this demand and is currently

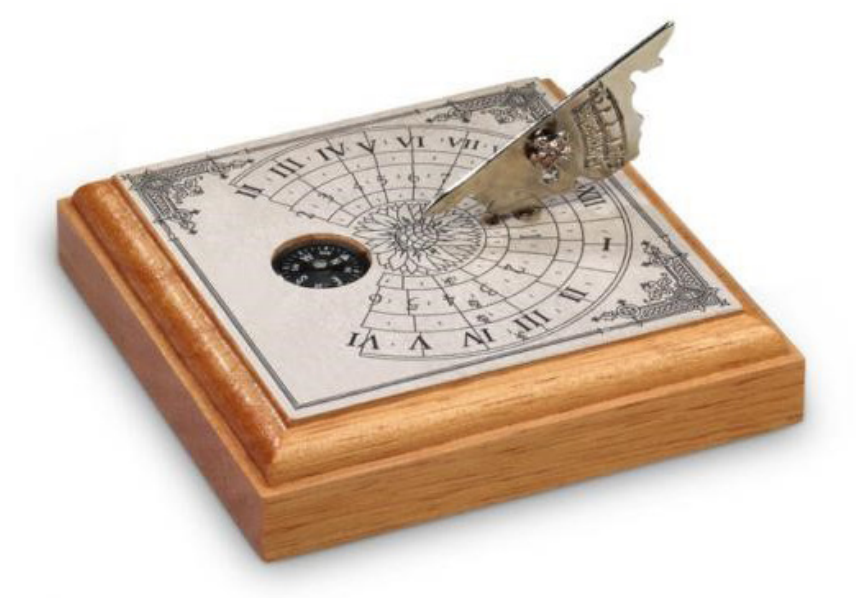

Figure 2. "Santa Cruz" Sundial. Source: Company portfolio. 
providing improvements. As to the package of the watch, there are possibilities for enhancements, such as a secondary use of the box. It could be used for embellishment and protection, changing its design to a configuration that allows the insertion of the game in it. Finally, an aspect that was perceived as being difficult to implement was the replacement of the product with a service. However, it is possible to provide a maintenance service for any defect of the product.

\subsubsection{Savings of natural resources}

For the "saving natural resources" criterion, the possibility of encouraging remanufacturing is suggested, since the product is very new and nothing is reused in manufacturing. However, features such as product dimensions and use of recyclable materials were evaluated with maximum score. The product dimensions are suitable for the roles it plays and a size reduction could result in difficulty seeing the hours or a distortion of the pointers, for example. In relation to the materials used, the wood does not use varnish and is therefore recyclable but not recycled. The paper, according to the company's website, is also recyclable.

\subsubsection{Use of renewable and sufficiently available resources}

In this regard, all the criteria were evaluated with maximum score, as follows: use of renewable resources, use of enough resources and minimization of the use of scarce resources. This is because the materials used (wood, paper and metal alloy) are renewable and are not rare.

\subsubsection{Prevention/minimization of hazardous substances' use}

All criteria were evaluated with improvement opportunities as the sealant applied to the wood is toxic and needs attention. For the management of risks inherent in the application of the products, the group suggests the use of PPE - Personal Protective Equipment (mask) in order to minimize the harmful effects of substances in the human body.

\subsection{Manufacture}

\subsubsection{Streamlining consumption (raw materials, energy, water)}

The criteria evaluated with improvement possibility were energy consumption and use of renewable resources. With regard to energy consumption, the suggestion is a planning of sequential production to assist in the consumption rationalization. Another point noticed was the fact that the energy used by manufacture machines is electric energy. There is a possibility to check the use of renewable energy. The consumption of materials and water was evaluated with the maximum score. The sundial production process does not use water as an input, only in indirect operations such as cleaning, and the dimensions of the sundial maximize the efficient utilization of wood used as raw material. The remains of this wood are donated weekly to a community garden.

\subsubsection{Prevention/minimization of pollution emissions and waste}

As the production process does not use water as main raw material, the prevention of wastewater is considered efficient. However, the prevention of exhaust air emissions can be improved, since the sealant at high levels can be toxic. Another improvement point observed was the waste prevention. Despite the fact that the sawdust is reused, the powder released in timber cutting steps can be harmful to joinery employees. The use of PPE (such as protective masks) in all operations in the woodworking shed is recommended. Finally, the prevention of noise emissions can be improved, since there is the presence of loud noise at all stages of production of the clock's wooden base.

\subsection{Distribution}

\subsubsection{Optimization of the packaging system}

The sundial packaging (Figure 3 ) consists of a cardboard box of $20 \times 17.5 \times 4.5 \mathrm{~cm}$. It is oversized for the product and does not protect it from any shocks or weights placed on the package. Research has identified that the parts that require protective packaging are on the top of the sundial (paper and gnomom). An improvement possibility is making a sort of lid covering only the top of the object, made of a similar wood from the basis. Another possibility raised was to shrink the package and to use a thicker cardboard, which protects the gnomom. Although the likelihood of the cardboard still be dispensed is high, this suggestion

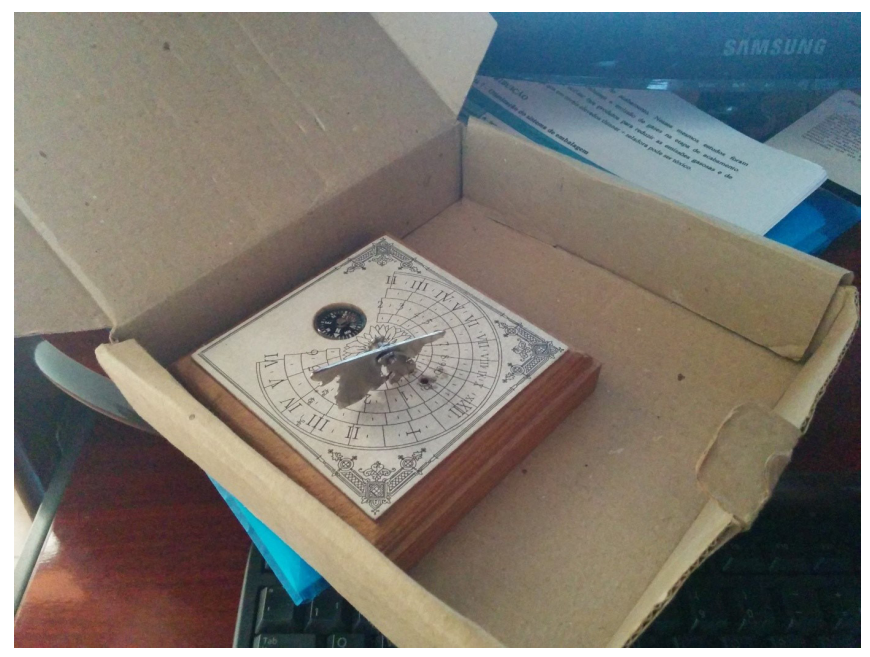

Figure 3. The product package. Source: Authors' file. 
would preserve the positive aspects of the recyclability. A reusable packaging system was discarded, because most of the end users of the watch are not direct customers of the company. It would be necessary to transport it twice (company - customer - user). The implementation of the logistics of this system would be too complex, therefore not feasible for the company.

\subsubsection{Implementation of an adequate logistics system}

Few improvement opportunities were identified in this regard, as the company works with requests for the Santa Cruz Sundial usually in quantities smaller than 500 units. At the same time, a fact that complicates the logistics planning is that the sundial demand does not follow a predictable pattern. In this situation, the company can produce many pieces in a month and none in the following year. An opportunity for improvement is the ability to transport several different products altogether with the sundial, so that may be few trips from the joinery (where the wood pieces are produced) to the shed (where it is assembled). There is also the possibility of adding the delivery of the request of the Santa Cruz sundial along with requests from other products, reducing the logistics operations.

\subsection{Use}

\subsubsection{Increase of product durability}

Regarding the product durability analysis, we identified both positive points and eligible improvements on the sundial. It has a "timeless design", i.e., the product does not depreciate over time, so this aspect was considered optimized and compliant. Nevertheless, there were found possible improvements regarding modular design. The product parts cannot be removed for cleaning, maintenance and repair. As to the cleaning, paper cannot be wet, making this procedure more difficult. One solution is the application of a material (for example, a special paper or plastic) that makes it impermeable and facilitates cleaning. In the aspect of ease maintenance, great difficulty was detected, since the gnomom and the compass are bonded and cannot be disengaged. And the aspect of facilitating repair, improvement opportunity is assigned as the gnomon is fragile and is not easily replaceable by the customer. Also, there is not a formalized maintenance service.

\subsubsection{Prevention/minimization of product utilization impacts}

Few variables were analyzed in this regard, since most of the items do not apply to the studied object. With respect to providing the user with information, maximum grade was assigned, i.e. the information provided is clear and meets the objectives. Along with the sundial, a small manual about the product use is provided to the user.

\subsection{End of life}

\subsubsection{Optimization of disassembly}

In the aspect relating the removal of the product, there is ample scope for improvement, as the Santa Cruz sundial is not a detachable product. Thus it is impossible to replace parts that can be damaged during use, which consequently causes the product to lose its usefulness when some of its pieces break. The main linking component used in the product is water based glue, which is permanent and confirms the statement that there's not a way of disassembling the product without breaking it. Another connection element found is a screw that joins two metal parts of the gnomom and is used only to give mobility of those parts and not to dismount the component. It is noteworthy that to remove this screw a specific tool is not necessary.

\subsubsection{Optimization of product reuse}

The product does not have possibilities for reuse. Its structure is simple, and is considered a "single structure", that is, you can only remove or access the other components with the destruction of the wooden base and the consequent destruction of the sundial as a whole. This characteristic brings difficulties to repair and replacement of these. Regarding the wear of components, it is emphasized that the metal part (gnomom) has a greater chance of wear over time, being extremely fragile, which may cause its rupture. The paper pasted on the wooden base has marks printed to aid marking time. Sun exposure can damage the printer and make it a lighter shade, which can greatly hinder the measurement of hours by the sundial.

\subsubsection{Optimization of recycling materials}

For minimizing the materials variety in the product, the elimination of the piece of paper pasted on the wooden platform is suggested, replacing it by crimped or printed markings on the timber. Thus, the use of glue for fixing the paper would also be eliminated, which would entail a high degree of recyclability. Since the product is composed essentially of wood, metal, rubber and paper, it is noted that the materials are compatible with future recycling. The lack of varnish in the wood also increases the recyclability of the product. However, the fact that the components are not easily separable complicates the recycling process. The materials are not marked to facilitate screening and selection of these parts for recycling the product. However, there is possibility of improvement: the elimination of paper and glue fixative, as suggested above, would reduce the number of components and facilitate the process of separation for recycling. Other suggestions, such as a 
locking system for gnomom instead of adhesive, would also facilitate the disassembly and recycling process.

\subsubsection{Appropriate discard of unrecoverable materials}

As noted earlier, all parts that make up the product are suitable for recycling. The Santa Cruz sundial does not use hazardous substances in any of its parts, thus the items referring to the table above do not apply in the analysis of this product.

\section{Conclusions and recommendations}

Some points called more attention during the research. These must be evaluated by the company and are described below:

i) Changes on the dipping compass and gnomom glue system to a locking system or some other solution: this aspect would facilitate the maintenance of the sundial, extending its lifecycle and making the final disassembly for material recycling easier. Solutions that address these aspects are consistent with the proposed value of the product quality and durability;

ii) Improvement of the quality of the gnomom alloy: This component broke twice during the analysis, making the clock lose its use and aesthetic functions. A higher quality piece could increase the usability and durability of the product;

iii) Changing the current package to one that enables the consumer to reuse or to one that protects more the product. Although these options represent two extremes solutions (reuse of package versus immediate disposal), both are valid and liable to implementation, depending on the company's objectives;

iv) Application of a sealer on the paper: this solution also prolongs the durability of the sundial, since the paper, when wet or spilled cannot be cleaned. Another suggestion pointed out by the research is to make the printed markings directly on wooden base: it could decrease range of materials, facilitating the disassembly for recycling. The printed markings could be sealed or crimped.

The graphic results of EcoDesign strategy wheel is presented below (Figure 4). To prepare this diagram the Environmental reference product profile was sketched. For this, for each axis (strategy) of the graph, the research assessed the performance of the product reference according to the listed items. Variations were analyzed related to the level of product components and selection of low-impact materials (stage 1), reduction of materials usage (stage 2), optimisation of the production techniques (stage 3) and distribution system (stage 4), reduction of impact during use (stage 5), optimisation of the initial lifetime (stage 6) and the end system optimization life (stage 7). The blue marking corresponds to an evaluation of the product as it is currently. The red marking matches to the situation purpose of the product, following the recommendations suggested by research. It is noticed that the greatest opportunities for improvement are in the categories of optimization of end of life system, reducing the use of materials (mainly referring to the packaging and paper) and optimization of production techniques, in the form of a system of sequenced production planning.

As a conclusion, this research has demonstrated the applicability of the proposed tool (Table 1), based on verification criteria linked to 14 points divided over seven stages of the product lifecycle. Despite the limitations of the survey (which was basically qualitative) and the non-application of a quantitative lifecycle assessment tool, it can be seen that it was possible to draw up a series of uncomplicated recommendations to the company. This way, it is intended to show that this tool can bring significant product improvements in environmental aspects, even in those produced by small and medium-sized companies, focusing mainly on the simplicity and viability of application. It is basically making the product lifecycle

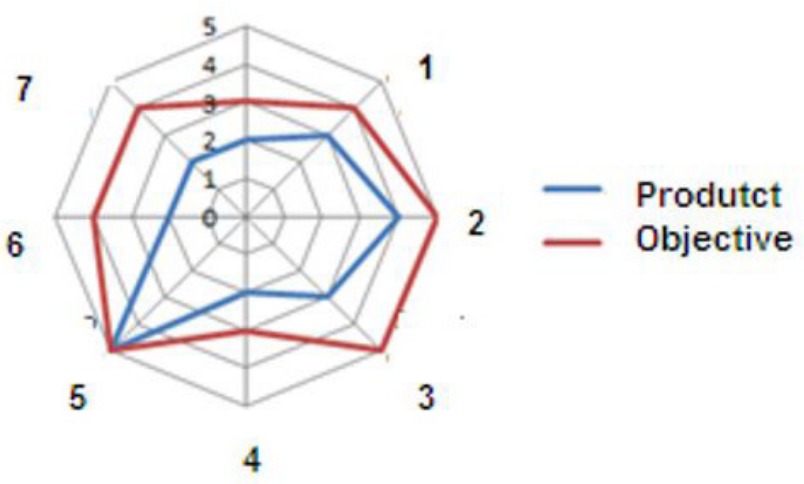

Figure 4. EcoDesign strategy wheel results.

Table 1. EcoDesign strategy wheel results.

\begin{tabular}{|l|c|c|}
\hline \multicolumn{1}{|c|}{ EcoDesign strategy wheel item } & Product & Objective \\
\hline @ New concept development & 2 & 3 \\
\hline 1. Selection of low-impact materials & 3 & 4 \\
\hline 2. Reduction of material usage & 4 & 5 \\
\hline 3. Optimisation of production techniques & 3 & 5 \\
\hline 4. Optimization of distribution system & 2 & 3 \\
\hline 5. Reduction of impact during use & 5 & 5 \\
\hline 6. Optimisation of initial lifetime & 2 & 4 \\
\hline 7. Optimisation of End-of-life System & 2 & 4 \\
\hline
\end{tabular}


more "transparent", drawing attention to aspects before disregarded.

\section{Acknowledgements}

This research was sponsored by the Brazilian National Council for Scientific and Technological Development (CNPq), an agency linked to the Ministry of Science and Technology (MCT) of Brazil and FAPEMIG - Foundation for Research Support of the State of Minas Gerais.

\section{References}

BOOTHROYD, G.; DEWHURST, P. Product design for assembly. Wakefield: Boothroyd-Dewhurst Press, 1991.

FORNARO, A. Águas de chuva: conceitos e breve histórico. Há chuva ácida no Brasil? Revista USP, n. 70, p. 78-87, 2006.

FRAZÃO, R.; PENEDA, C.; FERNANDES, R. Adoptar a perspectiva de ciclo de vida. Lisbon: INETI, 2003.

HOLlAND, M. M.; BLOOD, E. R.; SHAFFER, L. R. Achieving sustainable freshwater systems: a web of connections. Washington, DC: Island Press, 2003. 312 p.

HUANG, G. Q. Design for X. London: Chapman \& Hall, 1996.

KUO, T. C.; HUANG, S. H.; ZHANG, H. C. Design for manufacture and design for ' $\mathrm{X}$ ': concepts, applications and perspectives. Computers \& Industrial Engineering, v. 41, p. 241-260, 2001.

ROHRICH, S.S.; CUNHA, J.C. A proposição de uma taxonomia para análise da gestão ambiental no Brasil.
Revista Administração Contemporânea, vol. 8, n. 4, p. 81-97, 2004. http://dx.doi.org/10.1590/S141565552004000400005 .

UNITED NATIONS INDUSTRIAL DEVELOPMENT ORGANIZATION - UNIDO. Cleaner production toolkit: introduction into cleaner production. Geneve: UNIDO, 2001. Vol. 1 .

UNITED NATIONS INDUSTRIAL DEVELOPMENT ORGANIZATION - UNIDO. Life cycle assessment: what it is and how to do it. Paris: United Nations Environmental Programme, 1996.

VAN HEMEL, C. G. Ecodesign empirically explored: design for environment in Dutch small and medium-sized enterprises. 1998. Doctoral (Thesis)-Technical University Delft, Delft, 1998.

VAN HEMEL, C. G.; BREZET, J. C. Ecodesign: a promising approach to sustainable production and consumption. Paris: United Nations Environmental Programme, 1997.

VAN HEMEL, C. G.; CRAMER, J. Barriers and stimuli for ecodesign in SMEs. Journal of Cleaner Production, n. 10, p. 439-453, 2002.

WIKIPEDIA. EcoDesign strategy wheel. 2015. Available from: http://www.wikid.eu/index.php/File:DDG-2-5.png>. Access in: 17 Oct 2015.

ZHANG, B. et al. Why do firms engage in environmental management? An empirical study in China. Journal of Cleaner Production, v. 16, p. 1036-1045, 2008. 